[This is the pre-publication version of Henry, A., Davydenko, S. \& Dörnyei, Z. (2015). The Anatomy of Directed Motivational Currents: Exploring Intense and Enduring Periods of L2 Motivation. The Modern Language Journal, 99 (2) 329-345. DOI: 10.1111/modl.12214 0026-7902/15/]

\title{
The Anatomy of Directed Motivational Currents: Exploring Intense and Enduring
}

\section{Periods of L2 Motivation}

\author{
ALASTAIR HENRY \\ University West \\ Department of Social and Behavioural Studies \\ Trollhättan 46186 \\ Sweden \\ Email: al.henry@hv.se \\ SOFIA DAVYDENKO \\ University West \\ Department of Social and Behavioural Studies \\ Trollhättan 46186 \\ Sweden \\ Email: sofia.davydenko@hv.se \\ ZOLTÁN DÖRNYEI \\ University of Nottingham \\ School of English \\ University Park \\ Nottingham NG7 2RD \\ United Kingdom \\ Email: zoltan.dornyei@nottingham.ac.uk
}

\section{ABSTRACT}

Dörnyei and his colleagues (Dörnyei, Ibrahim, \& Muir, 2015; Dörnyei, Muir, \& Ibrahim, 2014;

Muir \& Dörnyei, 2013) have recently identified a particular motivational phenomenonperiods of intense and enduring motivation in pursuit of a specific goal or vision-that, although instantly recognizable, has nevertheless failed to receive attention in the research literature. The Directed Motivational Currents (DMCs) they describe differ from other experiences of intense motivation in that individual learning activities form integrated parts of a coherent motivational superstructure. The current article offers the first systematic empirical investigation of this motivational phenomenon. Focusing on periods of unusually intense and 
enduring motivation experienced by migrant learners of Swedish as a second language, the purpose of this interview-based study is to consider whether core characteristics of DMCs can be identified in participants' descriptions of sustained motivated behaviour, thereby considering the validity of the DMC construct. Results reveal that motivated behaviour is characterised by features similar to those outlined by Dörnyei and colleagues, namely the presence of a salient facilitative structure, the generation of positive emotionality, and the direction of motivated behaviour towards long-term identity-investment goals. This indicates that the DMC construct captures a unique form of motivation worthy of future investigation.

Keywords: motivation; Directed Motivational Current; goal; vision; behavioural routines; positive emotionality

In line with the socio-dynamic shift in L2 motivation research (Dörnyei \& Ushioda, 2011), where recognition is given to the situated complexity of L2 motivational processes, Dörnyei and his colleagues (Dörnyei, Ibrahim, \& Muir, 2015; Dörnyei, Muir, \& Ibrahim, 2014; Muir \& Dörnyei, 2013) have recently identified a particular motivational phenomenon—periods of intense and enduring motivation in pursuit of a particular goal or vision—-that, although instantly recognizable, has nevertheless failed to receive attention in the research literature. These goal-oriented surges of motivational energy, which Dörnyei and his team call Directed Motivational Currents (DMCs), differ from other experiences of intense motivation in that individual learning activities form integrated parts of a superordinate (and therefore complex) motivational superstructure. Once set in motion this structure assumes a life of its own, propelling the individual in the direction of a goal or vision, not unlike a current that transports various life forms and objects that enter its flow. Two features in particular, the directedness of a DMC (i.e., the presence of an end-term goal or higher-order vision to which the individual aspires) and the enduringness of self-propelling motivational processes, 
distinguish these motivational currents from other types of intense motivational experiences, such as for example those encapsulated in Csikszentmihalyi’s (1988) well-known theory of flow and in Deci and Ryan’s (1985) concept of intrinsic motivation.

Almost everyone has, at some time in their life, either experienced a goal-driven motivational surge or observed the manifestations of sustained, focused behaviour among those around them. Examples may include someone going on a successful diet, undertaking a challenging task and accomplishing it against all the odds, or developing a skill (such as learning a language) in record time by becoming almost obsessed with it. The phenomenon also exists at a group level, as demonstrated by effective political campaigns, charity drives or, in educational settings, classroom projects that galvanise learners into sustained, goal-focused action. Given the recognisability of such motivational currents and surges, it may seem strange that motivational phenomena similar to those outlined by Dörnyei and colleagues seem to lie beneath the radar of mainstream psychology and do not appear in the research literature in any recognisable guise. 
The reason for this omission would appear to be the limited temporal focus of most of the established motivation constructs in psychology. The usual practice of motivation research has been to examine motivation in terms of generalizable factors-such as expectations of success or perceptions of the values of success - in cross-sectional studies where focus is directed to single constructs and attention is paid to between-group differences. Thus, while much has been written about the impact of various goal-related dispositions on human action, Dörnyei, Henry and Muir (2015) point out that no mainstream motivation theory has yet taken the step of linking such dispositions with specific behavioural processes over time in order to examine how optimal combinations of certain structural features of the behavioural pathway can amplify the overall motivational energy released. Such issues, however, have been foregrounded by recent attempts to examine L2 motivation through more dynamically focused lenses (see Dörnyei, MacIntyre, \& Henry, 2015; Waninge, Dörnyei, \& de Bot, 2014) as part of an emerging emphasis on temporality and intra-case variation.

Not only does the lacuna in mainstream psychology make Dörnyei and his colleagues’ proposals worthy of empirical investigation, but the potential for creating a structured pathway in which, once generated, motivational energy can be harnessed in the direction of a superordinate goal, means that DMCs have important practical implications. Specifically, in creating a conduit within which language learning motivation can be sustained over time, a DMC, whether operating at an individual level (a particular learner) or at the group level (a particular class), has a transformative potential; it can provide an invigorating motivational boost to learning processes that might otherwise lack drive and direction. It is with this in mind that we now turn to examine the core features of DMCs and the motivational theories underpinning them. 


\section{CORE FEATURES AND THEORETICAL UNDERPINNINGS}

\section{Core Features of the Construct}

A DMC is "a prolonged process of engagement in a series of tasks which are rewarding primarily because they transport the individual towards a highly valued end” (Dörnyei, Ibrahim, \& Muir., 2015, p. 98). Functioning akin to an "injection of motivation into the system” (Dörnyei et al., 2014, p. 12), a DMC involves a greater sense of urgency than normal motivated behaviour. Such intensive, goal-directed activities often alter established patterns of day-to-day life, and people caught up in a DMC experience a unique sense of functioning beyond what they are normally capable of, or what they had even considered possible. Although DMCs display differences in terms of the specific combinations of factors that generate and sustain the flow of directed energy, as well as in the ways in which such energy streams are experienced, we can identify three key elements in all DMC-related phenomena that constitute the construct's core components: goal/vision-orientedness, a salient facilitative structure and positive emotionality.

Goal/Vision Orientedness. The first distinguishing characteristic of a DMC is the permanent presence of a clearly-defined superordinate goal, target or outcome; becoming the proficient TL-speaker/user one aspires to be. This has a gravitational effect on motivational energy, systematically channelling behaviour towards activities perceived as enhancing the likelihood of goal attainment and away from other, unrelated activities that compete for the learner's time. The directionality characteristic of a DMC—manifest throughout its durationinvolves the combination of a clearly defined end goal coupled with a vision of its accomplishment; seeing oneself in future situations using the language in interaction with others. Dörnyei and Kubanyiova (2014) define a vision as a goal that is enriched by the addition of the imagined reality of the actual experience of its achievement. As they explain, a group of students learning both an L2 and an L3 might, for example, have a shared vision of 
wanting to be multilingual as a consequence of a belief in the importance of reaching across language boundaries, envisioning themselves functioning in the future as a "task force that effectively promotes positive attitudes about multilingualism” (p. 83). The peculiar intensity of a DMC cannot be achieved without the addition of this visionary quality. Likewise, the power of the current will be dependent on the extent to which a visionary dimension is superimposed onto the guiding goal.

For a language learner caught up in a DMC, the future-oriented image of being a successful TL-speaker becomes part of the person they are. It becomes a part of their core identity. In such situations the ideal L2 self becomes chronically accessible in working cognition, a near-permanent constituent of the learner's active self-concept (see Dörnyei, Henry \& Muir, 2015). As Ushioda (2011) frames it, the learner’s TL-speaking self becomes immanently connected to actual lived experiences and to the central characteristics (e.g., sex, age, ethnicity, and various enduring personal preferences) of their own "transportable identities” (p. 16) (see also Zimmerman 1998). For someone in a language learning DMC, whose ideal L2 self has become part of their core identity, learning activities can rapidly transport them out of the everyday reality of a classroom environment or period of self-study, and into an imaginary world within which, for example, they envision themselves engaged in social interaction with other TL-speakers.

A Salient Facilitative Structure. The second distinguishing characteristic of a DMC is its structure. Functioning as a perceptual route map, the DMC's structure lays out the path towards and way stages en route to the accomplishment of the goal. It includes a facilitative element that provides opportunities for progress checks that serve to maintain the momentum of the current. It is for this reason that Dörnyei and colleagues describe DMCs as selfpropelling. Importantly_and it is in this sense that DMCs can be distinguished from other motivational concepts lacking an integrated behavioural dimension—-the motivational 
pathway that directs action towards the accomplishment of the task forms an integral part of the construct. Thus, unlike most previously proposed motivation constructs that separate motivated behaviour from the individual's internal or social motives, the concept of a DMC highlights the combination of motivational content and a fitting, situated behavioural pathway into which this motivation is channelled and through which the released energy is amplified.

The structure of a DMC has three defining components; (a) sets of recurring behavioural routines performed without the exercise of volitional control, where a totality of effort is aligned towards goal achievement; (b) processes of regular progress checks, where subgoals provide affirmative feedback; and (c) discernible start/end points. Although the nature and composition of the motivational processes of highly motivated language learners (individuals or groups) has not formed the focus of previous investigation, examples of extremely motivated learners with highly regulated learning behaviours, including systematic goal-setting processes, can be found in the literature on the interplay of identity and autonomy in language learning. For example, in his study of highly autonomous students taking a self-directed learning course in Japan, Murray (2011) found that these students set goals designed to facilitate movement from present to imagined future self-states. They were also alert to and documented even the smallest indicators of progress. In a study of highly motivated students learning several languages simultaneously through working in selfaccess centres in Mexico, Castillo Zaragoza (2011) found that they developed highly personalised programs of study, willingly devoting time working out of class in pursuit of the superordinate goal of developing a plurilingual identity.

A DMC has a clearly identifiable starting point where a combination of factors, cognitive and contextual, combine to set it into motion. Not infrequently, latent motivational energy is dramatically unleashed when triggering stimuli occur. Triggering events can be very different in character and, as can also be seen in Castillo Zaragoza's (2011) study, both instrumental and emotive in nature. While one of the highly motivated students interviewed in 
the study explained how a job on a cruise ship triggered a realisation of the importance of speaking different languages, and how developing plurilingual skills was very necessary for her, another explained how her drive to learn German was triggered by the experience of first encountering a Wagnerian opera. Even though a DMC can exist for a considerable period of time, there will be an end point, with the motivational current either abruptly dissipating (as on the achievement of a very specific goal), or gradually ebbing away when obstacles cease to be encountered or challenges no longer appear daunting. Individuals caught up in a DMC — and others in their immediate environment—are likely to be acutely aware of such turning points. It is around these transitions that changes in routines and behaviour are most evident. Because up to the accomplishment of a goal, other aspects of life can become secondary and a totality of effort is directed to its achievement, it is not unusual thereafter that the individual "might feel both physically and mentally drained and take time to adjust back to the everyday routine governing their lives before the DMC was initiated” (Muir \& Dörnyei, 2013, p. 363).

Positive Emotionality. The final defining characteristic of a DMC is the enjoyment experienced carrying out activities recognized as transporting the individual closer to their goal. Because in a DMC goals are strongly linked to identities and to a sense of actualizing one’s potential, learning and accomplishment can be understood as generating experiences of intense personal pleasure, satisfaction, and fulfilment that are very different from the more transient state of intrinsic pleasure generated, for example, from an isolated learning activity. Such emotions involve experiences of eudaimonic well-being (Waterman, 2008).

Eudaimonia, as Waterman explains, is "a constellation of subjective experiences including feelings of rightness and centeredness in one's actions, identity, strength of purpose, and competence” (2008, p. 236). Similarly, Norton (1976) describes it as the feeling of "being where one wants to be, doing what one wants to do" (p. 216). As, for example, Murphy’s (2011) research on autonomous language learners has shown, deeply satisfying 
experiences of fulfilment relating to processes of learning, progress, and achievement can have a highly positive impact on motivation. When, in her study, learners were engaged in activities that they perceived as transporting them closer to their idealized goals, they described sensations of pleasure, feeling inspired, and experiencing "a real sense of satisfaction” (p. 116). In a DMC eudaimonic experiences have a reciprocal effect. Like the DMC's facilitative structure, they contribute to the creation of an energy stream that becomes self-propelling. The enjoyment projected from the overall emotional loading of the target vision permeates each step along the way, even including engagement in activities that, outside the DMC stream, could seem tedious or boring.

\section{Theoretical Underpinnings}

The Extension of Goal-Setting Theory: Vision and Self-Concordant Goals. 
The motivational processes Dörnyei and colleagues identify as generating and sustaining a DMC are rooted in a body of established scholarship, and virtually all the major motivation theories offer some insights into the DMC makeup and functioning. In the following we highlight some of the key motivational processes that feed into the DMC construct (for a detailed discussion, see Dörnyei, Henry, \& Muir, 2015). Because of the directedness of DMCs, Locke and Latham's (1990) goal-setting theory offers several important lessons about how certain goal characteristics ensure cohesion for one's efforts and help to focus energy on the final goal achievement, the issue of commitment being amongst the most important. Generally, high levels of sustained behaviour occur when the individual is convinced both of the goal's importance and its attainability, and commitment is found when goals are both specific and difficult. However goal-setting theory offers little elaboration on what makes goals important or, for that matter, what commitment actually involves. For the DMC construct the nature of commitment is important; it is not just any goal that can form the basis of a powerful and enduring pathway of motivated behaviour. A DMC therefore involves three key extensions to goal-setting theory - the constructs of vision, self-concordant goals, and proximal subgoals - that, together, offer a theoretical account of the intense and purposefully directed aspect of directed motivational currents.

In a DMC vision, as previously noted, is the extension of an abstract, cognitive goal, upon which a strong sensory element is superimposed. This, as Markus and Nurius (1986) explain, involves the accessing of mental representations of tangible images related to achieving the goal and the imagined experience of having reached the desired future goalstate. This sensory addition increases the perceived reality and therefore the power of the desired target. This explains why the directedness of a DMC is connected to goals with vivid visionary characteristics, which, for a language learner, takes the form of a phenomenologically robust ideal L2 self.

However this sensory accompaniment is not the only way in which, in a DMC, goals 
are personalized, thus strengthening their motivational capacity. Goals that are genuinely 'owned' by the individual - that is to say those which are not merely self-determined (i.e. not externally imposed) - can generate powerful and prolonged levels of commitment. As Sheldon and his associates (Sheldon \& Elliot 1999) explain, goals that represent a person’s enduring interests and passions and which "belong to the self in a deeper sense” (p. 494), are not only pursued with vigour and determination, but also in a generally persistent manner and in ways that generate well-being and deep-seated contentedness (see also Sheldon \& Houser-Marko, 2001; Sheldon \& Elliot, 1998). In the pursuit of such self-concordant goals, goal-directed activities, including those that offer little or no intrinsic value, are willingly and repeatedly entered into.

When a person commits him/herself to a personally valued (i.e. self-concordant) future goal, a framework of proximal subgoals is generated. In a DMC this framework functions as a behavioural pathway that guides goal-directed action. Progression along this pathway from one proximal subgoal to the next means that motivated behaviour becomes self-renewing. That is, because in such a framework subgoals are clearly set out, and accomplishment involves moving closer to the ultimate goal, levels of commitment to future goals also become stronger with every subgoal that is attained (see Miller \& Brickman, 2004).

The Contrast with Flow. Finally, Csikszentmihalyi’s (1988) concept of flow, or the experience of optimal engagement in an activity, is important in understanding DMCs in that it refers to a state during which a person is wholly absorbed by and fully focused on successfully carrying out an ongoing task. However, there are also important differences. These relate both to the nature of the reward, and the timescale over which the two constructs operate. While in Csikszentmihalyi's terms the experience of a state of optimal engagement is generated by the intrinsically rewarding nature of a particular task (i.e. pleasure being derived from doing the activity itself), in a DMC the generation of an experience of optimal functioning (flow) is gained chiefly from the sense of being transported towards a highly 
valued end state. In a DMC the sense of 'being in the zone' comes therefore from ongoing engagement in tasks that are not necessarily enjoyable in and of themselves, but which are highly valued in that, with each step taken, the end state becomes perceptibly closer. 


\section{PURPOSE}

While in their initial work Dörnyei and his colleagues (Dörnyei, et a., 2014; Dörnyei, Ibrahim \& Muir., 2015; Muir \& Dörnyei, 2013) presented a theoretical construct likely to be recognisable to both teachers and researchers, adding purchase to their proposals by explaining how established mainstream theories of motivation can provide insights into the nature and functioning of DMCs, they have not yet offered any specific empirical data to corroborate the validity and main features of the proposed theory. Focusing on periods of unusually intense and enduring motivation experienced by learners of Swedish as a second language, the purpose of the current investigation is to begin filling this gap by examining whether the motivational features hypothesized by Dörnyei and his colleagues to be core characteristics of DMCs can be identified in these highly motivated learners' personal accounts, thereby bolstering the validity of the DMC construct.

\section{METHODOLOGY}

\section{Data Collection}

Not every motivated L2 learner will have experienced DMC-related motivational energy. To maximize the chances of identifying learners with DMC-type experiences, our study investigated a group of students liable to contain highly motivated individuals with clearly-defined goals: migrants developing new language-speaking identities and finding spaces for themselves in a new society.

Participants were recruited in a 3-stage process:

In stage one we asked teachers of Swedish at three different universities offering fast-track programs to migrants with academic backgrounds (one teacher at university A, two teachers at university B and one teacher at university C) to identify students they had taught in the previous eighteen months whom they believed to be particularly motivated. ${ }^{1}$ Contact (first by email, then by phone) was made with 21 students identified in this way, 7 from 
university A, 8 from university B and 6 from university C. As is common on such programs (Henry, in press a, in press b), these students came from all corners of the globe (Armenia, Australia, Belarus, Columbia, Congo, Iran, Ireland, Morocco, Macedonia, Moldavia, Pakistan, Romania, Syria, Ukraine and Yemen) and included spousal migrants, economic migrants and asylum-seekers. 
- In the second stage individual semi-structured interviews were carried out with these 21 students by the second author, using an interview guide covering the main dimensions of DMCs described above. During the interview each participant was also asked to plot their motivational trajectories on a simple graph, the aim being to identify whether a particular period of unusually intense motivation had been (or was being) experienced. Self-plotted graphs have been used as an elicitation device in a number of retrospective interview studies with a focus on temporal change (see e.g. Chan, Dörnyei \& Henry, 2015; Henry, 2015; Yashima \& Arano, 2015). While caution is needed in terms of imputing causality, the advantage of the method is that it enables participants to reflect on fluctuations in motivational intensity around possibly critical junctures. The interviews, all of which were conducted in Swedish, took place between February and May 2014 and lasted on average 50 minutes.

- In a third stage the first and second authors first examined the motivational trajectories that the participants had plotted in the preceding stage and, with these in mind, they subsequently listened to the audio-recordings of the interviews. The purpose in carrying out both of these steps was to identify individuals whose experiences of motivated behaviour corresponded with two basic criteria: (a) a trajectory including a distinct period/periods of very high motivation, which (b) the participant described in the interview as being unusually intense or greater than normal. Three participants (one from university A and two from university B) who met the above criteria most clearly were recontacted and invited to take part in a second interview conducted in May and June. The purpose of this follow-up interview, again conducted in Swedish, was (a) to focus more closely on the period(s) of intense motivation identified on the graph, and (b) to provide participants with the opportunity to describe more closely, expand upon, or clarify issues of interest arising in the first interview. The audio recordings from the first and second interviews with these participants were transcribed verbatim. The transcriptions resulted 
in a corpus of 42,000 words.

\section{Analytical Procedure}

Common to a number of qualitative approaches used by researchers with an interest in people’s conceptions of language learning and use-for example, Moment Analysis (Li, 
2011), Interpretive Sequential Analysis (Samata, 2014) and Interpretive Phenomenological Analysis (Henry, 2011) — is the understanding that the interview forms a site of meaningmaking, engaged in by both researcher and participant. As participants piece together understandings of their experiences, the researcher deploys theoretical knowledge in attempts to make sense of their articulations. This, as Smith and Osborn (2008) explain, involves a form of double hermeneutic; as participants try to make sense of their world, "the researcher is trying to make sense of the participants trying to make sense of their world” (p. 51). This involves the researcher adopting both an empathic and a critical standpoint: While trying to understand the situation as the participant sees it, there is also a need to step back, take a critical position, and understand the recounted experiences from theoretical perspectives.

Regarding the specific procedure applied, first the 3 x 2 transcripts were separately read through several times ${ }^{2}$, a process which generated general comments, notes, and annotations. Next, each transcript was read three additional times, first with a focus on expressions revealing goal/vision orientedness, second on utterances illuminating aspects of motivational intensity and the presence of a salient and facilitative motivational structure, and third on expressions of positive emotionality. Finally, extracts illuminating different aspects of each of these three parameters were collected together in order to identify commonalities and differences. In each stage of these processes, the focus shifted back and forth between empathic and critical standpoints.

\section{RESULTS AND DISCUSSION}

We first offer thumbnail portraits of the three participants (identified by pseudonyms), also specifying the periods of sustained motivation they describe in their interviews. Following that we present the data according to the categories of motivational intensity, goal/vision orientedness, motivational structures, and, finally, positive emotionality. In providing an account of core DMC features identified in descriptions of 
sustained periods of intense motivation, as much space as possible will be given to the women's voices, the main theoretical points summarised in the General Discussion. All of the data extracts presented are translations from Swedish by the first author.

\section{The Participants and the Periods of Sustained Motivation}

Athena. Until her arrival in Sweden, a year and half prior to the initial interview, Athena (35) had spent her entire life in Greece. In the wake of the crisis crippling her country's economy around the turn of the decade, her husband, a doctor, sought work abroad, finding a job at a teaching hospital in Sweden. Encouraged by his reports, especially of how their two preschool-aged children would enjoy growing up in Sweden, Athena and the children moved to join him eight months later. Having started out not knowing a word of Swedish, eighteen months later Athena had applied for undergraduate education in civil administration (which she duly started in Autumn 2014). As she recounts, her motivation began with her decision to study Swedish, and a period of intense and sustained motivation started when she enrolled on a ‘university provided program’ (UPP) 3 in September 2013 (Figure 1).

\section{[FIGURE 1 Here]}

Bina. First interviewed in March 2014, Bina (32), an asylum-seeker from Congo, had been in Sweden for just over 18 months. Having arrived alone, not knowing what had happened to the other members of her family, she had to wait initially in an asylum-seeker unit for a residence permit to be granted. As she was the only Swahili-speaking person in her unit, Bina describes a sense of joy when, after six months, she could leave every day to attend beginner-level ‘Swedish For Immigrants’ (SFI) classes provided by the local municipality. She describes two separate periods of intense motivation, one, lasting around four months, on the SFI program, and a second almost a year later, when she enrolled on the UPP provided by 
the university and from which she was recruited to the current study (Figure 2). Bina’s progress learning Swedish has been rapid and, like Athena, she hoped to begin an undergraduate program the following autumn.

\section{[FIGURE 2 Here]}

Oksana. Unlike the two other women, Oksana (26), who was born and brought up in Ukraine, had only been in Sweden for three months when she was first interviewed. Having met and fallen in love with a Swedish man who had been working in her home country, she joined him in Sweden in December 2013. While waiting for her residence permit in Ukraine, Oksana, without the benefit of a husband to talk to or any opportunity for formal lessons, did all she could to start learning Swedish. The period of intense motivation she describes commenced as soon as she arrived in Sweden (Figure 3). She describes being full of energy and making lists of all the things she needed to do to develop her language skills and, even before starting an SFI program in January, preparing for the challenge awaiting her and creating learning schedules. By the time of the second interview, however, Oksana describes a sense of tiredness. She recognises her motivation had dipped and learning Swedish no longer consumed her life in the way it had in February and March. In the short time she has been learning Swedish Oksana has achieved a staggering level of proficiency, evidenced not least by her ability to engage in a natural, self-confident manner in our interviews and to respond to questions with clarity and precision.

[FIGURE 3 Here]

\section{Motivational Intensity}

The most striking insight to emerge from the interviews is that during the periods of intense and sustained motivation, learning Swedish was not just important, but became an 
all-consuming preoccupation around which all other activities in the women's lives had to be accommodated. A totality of effort was aligned towards goal achievement. There is an abundance of examples of the ways in which motivational energy was channelled into language learning, and we offer several illustrations below to testify to the uncommon power of these motivational currents. As Bina explains, for a time her life revolved entirely around learning Swedish: " $80 \%$ of my time I wanted to be busy with the language. . . Everything was connected to SFI".

For Athena, who combines a full day of school with looking after her children, taking care of the home, as well as spending 4 to 5 hours a day studying the L2, motivation takes priority over everything: It affects my life. My motivation to learn Swedish in the way I want. It affects my life. In particular, she describes how she found herself making tough choices in this respect:

'Mamma, can you play with us?' 'No, I can't'. And I'm not happy that I need to have to say that.

I have lost a lot of time with my husband too. But he, you know what I mean. For example when it's 8 or 9 in the evening he's not asleep. We could sit and talk or do something together. But he understands that I have to study. I can't start at 11.00 o'clock when he's asleep for example.

Prioritising time for study is difficult when it impacts on other family members and Athena highly values the support and understanding she receives. Personal sacrifices are, in comparison, much easier to make: 
I used to go to the gym, but, but now it's not so easy since, as you can understand, there is no time.

I can't just study, you know. I like, I have always liked training, so that's why I bought myself a cross-trainer to have at home, so that I don't need time to go out to the gym. So that I can do that for example for half an hour at home and then continue studying...

Oksana’s motivation to learn Swedish also affected her family life. Overnight she and her husband switched from speaking English to only speaking Swedish:

We started speaking English and up to our wedding we spoke English. Then when I started SFI and asked them, can they evaluate what my level is, and they said that you have much, you have a good level but you can't talk. So when I got back I took a piece of paper and wrote 'In this flat we only speak Swedish' and put it on the fridge.

Like Athena, Oksana also recognizes how the need to create time for study has involved sacrificing social activities, and the following extracts also show how people around her noticed her total commitment:

I am thinking that, all those relatives of my husband. They found out that I was a little different. Because when I came I was very curious, liked to walk, like to sit and talk with them. Many hours. But when I started to study and got my goal, well then I didn't have time for that so much.

They [the other students] look at me sometimes. I'm thinking, they're looking because I'm sitting alone studying. I don't know how to explain for them. It's just that I don't want to waste time. I also want to talk with them. I also want to know something interesting. But the problem is the time I loose just sitting 
Although she is now better able to balance her language learning with other activities, Bina talks about how, in the beginning, not having social commitments enabled her to devote large amounts of time to learning Swedish:

When you are on your own, you have actually, you can only have motivation, and time for the language, and be completely absorbed with the language. And I think that that's why I have learnt so much during this time. Because I was alone and, yes, my thoughts are not with my family in Congo. So it's just Swedish. It is just Swedish.

\section{Goal/Vision Orientedness}

While all three women identify concrete subgoals - to gain the highest grade on an assignment, to complete a course within a self-imposed timeframe and to secure admission to the next-level course/program-the long-term, superordinate goals to which motivational currents are directed seem not as clearly defined. Bina, for example, talks in rather vague terms of wanting to work providing support in developing regions:

In five years I think, I hope, or I want to be, working for SIDA [the Swedish overseas aid agency] or another organization. Another Swedish organization. Somewhere in South America or Africa

Oksana, considering a similar horizon, talks of wanting to draw on her professional skills: Yes, yes, and I think that, I hope that, I can open a business because all my life I have dreamed of this. But I also, I am an accountant, I studied to become an accountant in my home country and, I'm thinking that I, yes, maybe start some small business and work as an accountant with bookkeeping, maybe have some employees. I think that's possible.

For Athena, identifying a distinct long-term goal is difficult as it kept shifting all the time: 
My goal became higher and higher all the time, and now it became higher again. Because in the beginning so I was going to learn a little Swedish. Then I was going to get a job, maybe at the airport, or something that I can get with my education. So, yes, OK, that's enough. But then, no. I must learn better Swedish. So I continued. So it became higher and higher all the time. And maybe, yes, this year it became higher. And now I have decided to continue studying for three years.

Thus, while for Bina and Oksana developing skills in Swedish appears to be a necessary part of reaching long-term goals, for Athena the relationship between language learning and distal goals is more complex. Learning Swedish, she initially reasoned, could get her out of the home. She then saw that it could also give her the opportunity to gain employment matched to her skills. However, having experienced success in her learning made her realise that she wanted to continue with Swedish. This in turn opened up opportunities as she recognised how her language skills could enable her to secure a place on an undergraduate program, meaning that employment ambitions also become upwardly revised.

The long-term, aimed-for outcomes to which these motivational currents are directed can thus be seen as investment goals. Not only is language learning fuelled by pragmatic reasons—an investment in future careers—it is also an investment in the language and language practices of a desired community of Swedish speakers (Norton, 2013), with all three women emphasising the desire to affiliate with Swedish speakers and to integrate into Swedish society:

I did all of my homework. I was motivated. I read a lot and I wanted to be finished with SFI within a year. Not just because we got a bonus, money, but since I felt that if I finish quickly then, I was thinking, then I can get into society quicker. [Bina] 
When I am 30? Oh, I see myself as, ermm, a very independent, how do you say? Yes, independent, that's what the word means, person who knows what they want and I want to have some accomplishments behind me, like I did now, and then I can know that I am a worthy member of society. [Oksana]

I want to get better into the system. That's my dream, you could say, and you can do that with a job. So I dream about a job and not studying more. [Athena]

It is noteworthy, however, that these goals are neither particularly explicit, nor welldefined. Although Athena and Bina both describe identifying self-in-the-future proxies - I thought, when, when are we going to speak like them?[Bina], His pronunciation isn't so, so good after so many years in Sweden, but he writes wonderfully. But I said, 'OK, I can also do that if I want to' [Athena] - it is interesting that none of the women described future scenarios in ways that would indicate the operation of the sorts of phenomenologically powerful selfin-future images that Dörnyei and colleagues suggest are characteristic of the types of goals that generate and propel a DMC. To this we return in the general discussion.

\section{A Salient Facilitative Structure}

As discussed earlier, the trajectory of a DMC involves the successful match of a targeted goal/vision with an adequately tailored pathway. It is to this tailored pathway that we now turn, looking respectively at, (a) the presence of recurring behavioural routines, (b) processes of regular checks where subgoals provide affirmative feedback, and (c) the pathway's discernible start/end points.

Recurring Behavioural Routines. When caught up in a DMC, goal-directed activities are performed with a high degree of consistency. Routines are established and individuals in the current and people around them are aware of repeated patterns of goal- oriented behaviour. These routines create a type of 'motivational autopilot', which Dörnyei 
and his colleagues suggest becomes “an integral part of the DMC experience” as engagement occurs without the exercise of volitional control.

All of the women talk about how study routines became an integral part of their lives. Athena, for example, tells of how weekday-evening routines were established where she would study from 10 p.m. through to 2 a.m.:

We would eat together, and play with the kids, and then I started studying at ten, or half ten in the evening until two. /. . . / Maybe some days I fell asleep in front of the computer. Other days my husband would say 'OK, I can lie on the sofa', so he was with me. But of course he fell asleep. But I knew I had someone with me. /. . ./ I didn't feel good, but I wanted to reach my goal.

Bina describes similar routines with evenings taken up with study: I read a lot and I just wanted to read more. After I had made food, after I had eaten, I'd get my books. And I started. Now, she says, patterns of study have changed. Instead of spending two to three hours every evening studying at home, this work now takes place at the school: I know that if I am at home I might not finish a book. So it is better to stay in school, two hours, sometimes three. I read and I can finish a book. This new routine came about partly because she has met another highly motivated student whom she enjoys working with:

I stay in school and do my assignments, because it is here, here I can concentrate /. . . / And now I have met a woman from Sri Lanka who, she is also motivated, and sometimes she stays with me. We study together. What I don't understand, she helps me with. What she doesn't understand I help her with if I know. I help my friend and so it is great.

Oksana, too, describes how she developed routines for learning that enabled momentum to be maintained. She has learnt to be economical with her time and has established patterns of working where periods of study are 'scheduled' in the spaces between lessons and on her 
journeys to and from school:

O: We have a half an hour break. And then we have an hour. And then we have another half hour. Two hours break is too much. Better to make it fifteen, thirty minutes and fifteen.

I: What do you do during breaks?

O: I study. /. . . / I want to keep up the pace. And study during the break. Or when I go home on the bus I immediately start studying.

Processes of Regular Checks where Subgoals Provide Affirmative Feedback. A second element propelling a DMC forward is the sense in which sub-goals provide a series of regular checks that allow progress to be tracked and function as proxy targets and evaluative criteria. Through close, step-by-step, stage-by-stage monitoring, impetus is provided for continued effort and momentum is maintained. When the women talk about sub-goals, horizons are generally mid-range, often the completion of a course or a module. With affiliation and integration as long-term goals, the route is marked off in waystages, each subgoal a step closer to the final destination. As Oksana explains, subgoals help her keep on track:

When I came here at the end of December, I got some paper and wrote down everything that I wanted to do. I wrote down what I would do during the next six months. I wrote down everything. /. . / And also certain times.

Progress-checks have an important function in sustaining momentum. For Athena, knowing she is on course, that is, realizing that she is on the way to accomplishing important goals, helps her maintain energy when working late at night:

. . . there were some times when I felt, I got crazy, and I said 'OK, I need to stop this now, I'm not going to do it. It's not working'. But at the same moment I said 
'oh no, I can't stop now, now I am, now have reached this half-goal I have to continue.'

I felt so tired. So I said to myself 'do you see the result? That every day you can, you can speak better and better and better. You can write better and better and better.' And it was like saying to myself 'You have to continue and not give up.' So it was the results in daily life that gave me confirmation.

For all three women, feedback plays an important role in maintaining motivational momentum, and therefore their teachers' responses are identified as playing a crucial role in creating sustained energy:

Every assignment we submit we get comments back. And the comments are better and better all the time. That I have developed my language level so much makes me happy. And it gives me the motivation to continue you could say. [Athena] Today I can get my paper with less of my teacher's pen, but if I just sit back, OK, now, now I can speak Swedish, I am super, next time I get the paper back there can be a lot to correct. So you must, it's like you have to continue. [Bina]

In addition to teacher-provided feedback, the positive responses of others also contribute to maintaining motivational currents. Positive comments, as Oksana explains, provide evidence that effort yields results, which in turn creates positive energy: I am happy because I have worked. There is a result. A harvest from my work so to say. Valuing positive responses from L1 speakers in a similar way, Athena tells of how she actively seeks out opportunities to access a more ecologically valid form of feedback, and how important this is in generating continuing motivation:

After I've got feedback from the teacher, I then send it for example to some friends who can speak Swedish and they say 'Have you written this yourself? Oh I am so impressed.' And this also gives me motivation. That I do something. 
That I have a result. For me it's about when I get a result. I can continue to go onwards and I think that this has the best motivation.

Feedback loops—-the identification of tangible 'results,' teachers' comments and the responses of L2-speaking others-function in ways that make achievements visible as viewed through the eyes of important others. Confidence in their ability to succeed is generated, self-efficacy is enhanced and a conviction that autonomous learning practices are successfully moving them towards long-term goals is instilled. Moreover, these forms of affirmation are highly instrumental in maintaining motivational momentum and acting as fuel for subsequent efforts.

Explicit Turning Points. Although, in a retrospective study design it is hard to specify the exact dynamic shape of the motivational currents (a longitudinal design would be needed to properly determine whether, once triggered, streams of energy grow incrementally or level off), what is clear is that they can materialise and dissipate rather quickly. The lifespan of a DMC can never be determined aforehand and, just as rapidly as it is set in motion, a current's power can abruptly cease. It is around these transitions that changes in routines and behaviour are most evident. For each of the four periods of intense motivation identified in the data, the unleashing of motivational energy is sudden. For Oksana, waiting at home in Ukraine to come to Sweden, and Athena, spending her summer preparing for the UPP, anticipation preceded the rapid release of energy that set the currents in motion. For both periods of intense motivation described by Bina (first SFI and then the UPP), the current flows into life in epiphanic circumstances where visions of future possibilities suddenly materialise:

It was a feeling, it was so exciting, because it was that, it gave me the chance to get out. To get out. Not just from the camp, but also from, to get out of the camp and to get, just a little bit, into society. /. . It's like, you know, you are in prison. And you see that you 
can walk. OK, you have to come back. But you can walk.

/. . . / And it is so exciting. Now I am going to learn. It's excitement you cannot 
explain. I think it's like, I don't know. It's, it's fun. And strange actually, because I am an adult, but you feel like a child.

Because everyone is young and the atmosphere is fun. It is really fun. And I haven't ever seen so many people in the same place. It was the first time I had had such an experience. Because at SFI it was just immigrants actually who were studying there, for immigrants. But here at university it's not like that. So I was just, 'Wow'. It was a big thing.

Although not as rapid as the sudden release of energy precipitating currents of heightened motivation, all three women describe how, after a period, they experience the motivational stream slowing down. For Bina, intense motivation endured for the entire period of her SFI studies. Not only had SFI become the most important thing in her life'Bina, you know, it does something to you, SFI,' her friends tell her-but she also describes how, once the program had been completed, she assumed she would be finished learning Swedish and could start looking for employment. Realizing SFI was not the end, and that she would need to begin another program, she found herself not as motivated as before; the current had rapidly ebbed away:

What am I going to do after SFI? I want to be active now after SFI. So no, I understood that 'no, you can't be active after SFI.' I had many expectations, but this was not to be. So it affected my motivation.

For Oksana the motivational current waned after three months of very intense study: When I came here I had a list of what I would do, so I was very active and did many things during a period, a few months. So now I have a little time over. I am also a little tired, because I was so active.

Moreover she tells how her husband and his family encouraged her not to push herself too hard, and how this too impacted on her motivation: 
They think that I have studied really quickly. But they also think that I shouldn't be so focused. I must be more relaxed. Because that is a Swedish way of looking at things, I think. Doing everything like I do, is not necessary. Or being so ambitious or sometimes finding it hard to be relaxed. Because they think I need to be more relaxed and, yes, enjoy my life.

Like Oksana, Athena describes how, coming towards the end of the program, not only was she looking forward to the summer break, and returning to Greece to visit her parents, but also how she experienced a sense of tiredness. Although still highly motivated, working late is not always as easy:

The day before yesterday I was sitting on the bed changing into pyjamas and I couldn't. I had hardly any pulse. So my husband said to me 'you must sleep now.' 'No, I need to study' I said. 'No, Athena, you need to sleep now and I won't hear another word.' So there are days when I get very, very tired. And it's not good for my health. I know that. But I want to keep up with the program.

And I don't want to get behind the others, you know.

\section{Positive Emotionality}

In a DMC, positive emotions are experienced in the sense of well-being attaching to the actualization of one's potential in the pursuit of a highly self-concordant ultimate goal. The co-relatedness of these different forms of eudaimonic pleasure is frequently in evidence when the women describe the emotions connected with learning processes and desired endgoals, for example when Athena reflects on how her life has changed over the preceding eighteen months:

We were in Greece. We had a house, our own house. OK, we didn't have much money. But that didn't matter. We survived. But everything changed enormously, very suddenly. But it's going really well. And I have never said that, for example 'Oh, I 
came to Sweden and now I have to learn a new language.' I enjoy it, actually. And I am probably a better student than I was before.

Oksana, too, describes positive feelings of self-fulfilment in progressing onwards towards her goal, as well as a sense of excitement in being able to put her language skills to use:

'OK, you can start on the ' $D$ ' course without doing a test. I can see that you know Swedish.’ I was so happy that I hugged her. Was so happy. Thank you so much. And then I started on the 'D' course. It was harder. I was so happy. And I could see it was hard. And it was for me. I wanted to study.

I feel really good when I learn new words. Sometimes it can happen that I can learn a new word and meet, someone says the same word, and I'aha, I've met that word so I know it.' And maybe a little adrenalin too because you, like, yup, I know that.

Reflecting on the experience of learning in a university environment, Bina’s words similarly indicate twin sources of positive emotions; self-fulfilment as she gets closer to her goal and, in a new and stimulating environment full of possibilities, a feeling of being intensely alive:

When I come here, the way I walk is different. I feel good, yes. Different feelings. I feel that coming here is big. It's better. I am closer to my goal. Everything is in Swedish. And you get that feeling in your stomach. In my stomach. Because I have more motivation and I think 'now you are here.' Whatever you want to be. And after this something big is going to happen. That's how I felt. So that's why my motivation is high, high, high. But it is interesting. It's very interesting. And as I said, I have applied to university and I feel, I really have motivation. I feel great. /. . . I I feel fantastic. I feel happy, I like everything I see around me and I feel that I, I already belong to the university and, it feels just wonderful. 
It is not only a general sense of fulfilment experienced in developing skills in Swedish that the women describe, but, because they are caught up in a DMC, the ordinary daily routines of study can also generate feelings of excitement and joy. As we have seen, for Athena, routines of night-time study were physically demanding and impacted on the normal rhythm of family life. Her ability to repeatedly sit down at her desk at ten o'clock at night was made possible not just as a consequence of the recognition that her efforts were bringing her closer to her goals, but also because learning Swedish generated feelings of enjoyment and satisfaction:

It was maybe only me who studied so much, to two or three at night. The others were like 'oh, why do you sit there so long?' 'Because I want to'. 'I want to know why this is as it is, why this grammatical rule is so, why?'

I like it. I like what I am doing. So time always went quickly.

The sense in which, even when she is tired, Athena finds learning late at night enjoyable, the hours rapidly passing by, is echoed by Bina when she talks about how staying late at school studying together with another student, is never a burden:

It went very quickly because we didn't want to say goodbye to each other. We really wanted to continue. But she is married and she has to get home. She must. Because we would very happily stay together and work more. And it's fun to be studying together actually.

In circumstances that might normally be unthinkable-neither Athena nor Bina having previously gone to such lengths to achieve a goal—being caught up in a DMC overrides tiredness, generates recurring experiences of deep-seated satisfaction, and permeates the learning process with experiences of positive emotions. Rather like the explorer envisaged by Dörnyei, Ibrahim and Muir (2015, p. 101) who “finds every new step into the unknown thrilling in spite of the often considerable physical challenges,” the three women experienced 
excitement in developing language skills and intense feelings of satisfaction in the realisation of personal potential. Just as for the explorer, these eudaimonic experiences are generated both by the prospect of conquering the summit and by the stages of the journey that, slowly but surely, transport them there. 


\section{GENERAL DISCUSSION}

We turn now to consider the ways in which our results offer support for the validity of the DMC construct, focusing particularly on goal-orientedness and vision. Setting out on this study our aim has been to discover whether the features that Dörnyei and colleagues describe as characteristic of DMCs could be detected in descriptions of periods of intense and sustained motivation provided by migrant learners of Swedish and, by so doing, to consider the validity of the construct. The insights we have gained offer support for the contention that powerful long-term motivational currents do exist, and that the DMC construct does capture an intense form of motivation characterised by a positive emotional loading that is upheld by the existence of a salient facilitative structure. The intensity of these women's motivated behaviour-working into the night, staying behind at school for two or three hours at the end of the day, and routinely cutting short breaks to make time for study—is evidence indeed of the capacity, when in a DMC, to function over a sustained period of time at levels much higher than normally experienced, or indeed believed possible. Such behaviour, our analyses indicate, can be sustained as a consequence of processes of personal goal-setting and appraisal, through positive self-appraisals generated by progress-indicators (tangible results in both formal learning/testing contexts as well as natural language use), via the receipt of positive feedback from teachers, and from encouraging responses (both solicited and spontaneous) from L2-speakers. Furthermore, even though the participants mention the social sacrifices that such dedicated and focused motivated behaviour entails, and, especially towards the end of DMC periods, a creeping sense of tiredness, learning activities are nevertheless pursued with vigour and with a sense of satisfaction and personal fulfilment.

However, with regard to goal-orientedness - that is, the presence of well-defined targets or outcomes functioning as a focus for energy and providing cohesion for effort- that Dörnyei and colleagues argue is characteristic of DMCs, our analyses failed to reveal long- 
term goals that were explicitly defined. Nor did the women give voice to idealised versions or describe specific visions of future selves. Does this mean then that it is possible to experience a sustained period of intense motivation without an end-goal/vision in mind? We think not.

Rather, the reason why we did not find such descriptions may have more to do with the specific situation of these women. For all three participants, the process of moving to Sweden has been a life-changing experience; therefore developing a space for themselves in Swedish society is, in itself, a powerful visionary journey. This backdrop intensifies the significance of the meaning of their statements that all-out effort can enable them to get into society quicker (Bina), to get better into the system (Athena) or to legitimise their status as a worthy member of society (Oksana). Although neither clearly-defined nor tangible, these statements are nevertheless a shorthand for hugely personal, all-encompassing visions that constitute the goal-directed axis of their motivational currents. In their unique positions as migrant women in a new and challenging cultural context, becoming a worthy member of society constitutes both a highly self-concordant goal and an idealised identity as powerful as any.

To understand the potency that the fusing together of this highly self-concordant goal and desired future identity has in setting in motion intense, enduring and directed flows of motivation, we would like to return to Bina's experiences of finding herself in a university environment and the vision of another, alternative self, that is generated there: When I come here, she says, the way I walk is different. I feel good, yes. Different feelings. I feel that coming here is big. It's better. I am closer to my goal. Whether we choose to conceive of this ultimate goal/vision in terms of an integrative motive (Gardner, 2001), investment (Norton, 2013), or the desire to become one’s ideal L2-speaking self (Dörnyei, 2009), the point is that it is one which operates at a heightened level of phenomenological abstraction. It is a feeling. A sensation. A sense of being or becoming. It is, as Levin (2000) puts it, a "rich and textual picture of what success looks like and feels like. It is a vision that enables the individual "to transport himself or herself to the future, so to speak, to witness it and experience it” (p. 95). It 
is something so intensely powerful that, for a time, it involves the sensory experience of being the person, or being close to the person, that one aspires to be.

\section{IMPLICATIONS FOR PRACTICE}

In this section we discuss the ways in which DMCs comprising structural components similar to those evidenced in the current study can be fostered in classroom contexts. To the best of our knowledge, sustained, goal-directed motivation has not previously been explored in mainstream psychology paradigms, let alone in SLA. A DMC is thus a highly novel concept. And, while there is undoubtedly value in closely examining the motivational processes of individuals who, like the women in our study, approach the task of mastering a foreign language with uncommon drive, persistence and vigour, learners such as these, as we know too well, are only rarely encountered in the instructed learning environments of most secondary and tertiary educational systems. Indeed, beyond recognition of the important constitutive role in the DMC’s facilitative structure played by teachers' systematic encouragement and focused feedback (as well too as the need to sometimes help highly motivated learners such as Athena and Oksana to de-dramatize the learning process), it might be argued that the DMC construct has few implications of value to practitioners. Does then the DMC phenomenon offer a relevant contribution to second language teaching, and if it does, in what sense?

Although, as empirically demonstrated in the study, the motivational surges of energy characteristic of DMCs are uniquely constituted and follow highly individual trajectories, it is also possible to rig sets of conditions within which a DMC can be nurtured into existence. Because it "allows for the laying out and controlling of an intricately structured pathway" (Muir \& Dörnyei, 2013, p. 369), the language classroom provides an ideal context for the creation of a DMC. Although rarely explored in SLA research (although see Dörnyei \& Murphey, 2003), in other fields, most notably organizational psychology, motivational 
research tends to be centred on group dynamics and processes at the group level. In these traditions important underlying recognitions are, first, that groups and organisations have a life of their own, and secondly that, within a group, people behave differently than as individuals removed from the group context.

In the emergence of a collective motivational energy within a group, processes of emotional and cognitive contagion - the catching or 'infection' of the cognitions and emotions of others - play an important role (Barsade, 2002). Because emotional contagion in particular has ripple effects, the enthusiasm and positive emotional loading generated by an activity or project can serve to infuse an entire group with a positive mood. This, in turn, goes on to impact positively on attitudes and the group's collective motivation. A similar effect, described by Aarts and Custers (2012), is goal contagion, where collective goal pursuit can be triggered and where individual goals are inferred from the behaviour of others. Importantly, promising research extending Csikszentmihalyi’s (1988) original concept of flow from an individual to a collective experience has also emerged in recent years. In this work flow is conceptualised as “a property of the entire group as a collective unit” (Sawyer, 2006 p. 158). While Sawyer (2006) suggests that 'group flow' - as he terms it - can arise among a group of people if the group has a common goal or task to which everyone is united in their efforts, Gaggioli et al. (2011), with a focus on the educational implications, argue that group flow can emerge in an instructional context when there exists a shared collective intention. Moreover, Shernoff (2013) suggests that, given the right type of challenge and the right type of support, group flow can be created in educational settings. To create flow in a classroom, Shernoff maintains, requires the existence of a challenge of sufficient complexity and perceived importance, which is accompanied by clear goals and opportunities to demonstrate performance. Provided there is also a supportive environment (characterized by positive relationships between teachers and peers, the support of experiences of autonomy and perceived competency, constructive feedback and opportunities to be active and 
interactive), whole classrooms of students can experience periods of optimal engagement.

In a language learning context, Dörnyei and Kubanyiova (2014) explain how, in relation to a particular goal, groups of learners can possess a shared vision both about the futures of individual members as well as the future state of the group as a whole. Building on these ideas Dörnyei, Henry, and Muir (2015) describe how, just like the motivational currents identified in the present study, DMCs containing specific starting points, welldefined final goals, and clear structures that facilitate progress can be created at a group level in the form of intensive group projects, and they set out seven frameworks which can be used to generate group-DMCs in the L2 classroom.

\section{CONCLUSION}

To the best of our knowledge, the phenomenon of a sustained, goal-directed motivational process has not been previously theorised or explored in mainstream motivational psychology paradigms, let alone in SLA. Therefore, the notion of 'Directed Motivational Currents' offers a novel and potentially far-reaching theoretical construct. However, no matter how much this construct is underpinned by arguments that draw on established motivational principles, or how intuitively compelling it might appear, in the absence of any close investigation of the nature of the experiences of highly motivated language learners, the proposal lacks empirical grounding. This recognition served as the main motivation for our study and we believe that the findings presented in this paper go some length towards lending support for the construct’s validity. Specifically, our investigation provides affirmation for the existence of surges of intense and sustained motivational energy, as well as for the presence and operation of three features hypothesized to be characteristic of DMCs: their goal-directed nature; their self-propelling capacity as a function of a salient facilitative structure; and the positive emotional loading that permeates every step of the motivated behavioural process. 
Besides the theoretical relevance of conceptualising motivational surges, DMCs also have a great deal of practical potential. Through the generation of a shared vision and the creation of group energy through processes of cognitive, emotional and goal contagion, DMCs, like group flow, can operate at a collective level, driving for instance whole-class and school-wide undertakings. As such, they can be used for developing effective motivational interventions to bring, for example, new leases of life into learning environments or activities that have become stagnant or inert. Along with the conceptual papers mentioned earlier, and Dörnyei, Henry and Muir’s (2015) book-length treatment of the topic, the current study marks an important start in what may prove to be an exciting new direction. Future research will need not only to examine the different types of DMCs that might exist in different settings, among different learners, and in different group constellations, but also the precise ways in which the transformational potential of DMCs can optimally be harnessed.

\section{ACKNOWLEDGMENTS}

We would like to thank the three anonymous reviewers for their close scrutiny of the paper and very useful comments. We are also indebted to Heidi Byrnes for the advice we received at the pre-review stage. This has been invaluable, not only in terms of the current paper, but also in bringing important perspectives to our ongoing work on DMCs. Finally we wish to extend our sincerest thanks to the teachers and students at the participating universities, not least the three outstanding language learners whose experiences form the basis of this research.

\section{NOTES}

1. At university A the second author was the teacher who identified motivated students.

2. Because the aim of interpretive analyses is to make sense of the content of participants' accounts, a detailed transcription of prosodic aspects of recordings is not provided. 
3. In Sweden, two types of language programs are offered to migrants. The stated aim of 'Swedish for Immigrants' (SFI) courses is to "provide adults who lack a basic knowledge of Swedish with opportunities /. . . / to communicate in orally and in writing.” Once these courses have been completed migrants who have completed upper secondary education can enrol in language programs that provide university entrance qualifications. These programs are often offered by universities and differ between institutions. To safeguard participants' anonymity, rather than using the actual names of these programs, they are referred to as 'university provided programs' (UPPs).

4. The trajectories shown on the graph represent those plotted by the participants in the initial interview and updated in the second interview. The months were added subsequently to indicate the period during which the intense motivation existed.

\section{REFERENCES}

Aarts, H., \& Custers, R. (2012). Unconscious goal pursuit: Nonconscious goal regulations and motivation. In R. M. Ryan (Ed.), The Oxford handbook of human motivation (pp. 232-247). New York: Oxford University Press.

Barsade, S. G. (2002). The ripple effect: Emotional contagion and its influence on group behavior. Administrative Science Quarterly, 47(4), 644-675.

Castillo Zaragoza, E. D. (2011). Identity, motivation and plurilingualism in self-access centers. In G. Murray, X. Gao, \& T. Lamb (Eds.), Identity, motivation and autonomy in language learning (pp. 91-106). Bristol, UK: Multilingual Matters.

Chan, L., Dörnyei, Z. \& Henry, A. (2015). Learner archetypes and signature dynamics in the language classroom: A retrodictve qualitative modelling approach to studying L2 motivation. In Z. Dörnyei, P. D. MacIntyre , \& A. Henry (Eds.), Motivational dynamics in language learning (pp. 238-259). Bristol, UK: Multilingual Matters. 
Csikszentmihalyi, M. (1988). Introduction. In M. Csikszentmihalyi \& I. S. Csikszentmihalyi (Eds.), Optimal experience: Psychological studies of flow in consciousness (pp. 3-14). Cambridge: Cambridge University Press.

Csizér, K., \& Dörnyei, Z. (2005). The internal structure of language learning motivation: Results of structural equation modelling. Modern Language Journal, 89, 19-36.

Deci, E. L., \& Ryan, R. M. (1985). Intrinsic motivation and self-determination in human behaviour. New York: Plenum.

Dörnyei, Z. (2009). The L2 motivational self system. In Z. Dörnyei \& E. Ushioda (Eds.), Motivation, language identity and the L2 self (pp. 9-42). Bristol, UK: Multilingual Matters.

Dörnyei, Z., \& Ciszér, K. (2002). Some dynamics of language attitudes and motivation: Results of a longitudinal nationwide survey. Applied Linguistics, 23, 421-462.

Dörnyei, Z., Henry, A., \& Muir, C. (2015). Motivational currents in language learning: Frameworks for focused interventions. New York: Routledge.

Dörnyei, Z., Ibrahim, Z., \& Muir, C. (2015). ‘Directed Motivational Currents’: Regulating complex dynamic systems through motivational surges. In Z. Dörnyei, P. D. MacIntyre , \& A. Henry (Eds.), Motivational dynamics in language learning (pp. 95-105). Bristol, UK: Multilingual Matters.

Dörnyei, Z., \& Kubanyiova, M. (2014). Motivating learners, motivating teachers. Cambridge: Cambridge University Press.

Dörnyei. Z., MacIntyre, P. D., \& Henry, A. (Eds.) (2015). Motivational dynamics in language learning. Bristol, UK: Multilingual Matters.

Dörnyei, Z., Muir, C., \& Ibrahim, Z. (2014). Directed Motivational Currents: Energising language learning through creating intense motivational pathways. In D. Lasagabaster, A. Doiz, \& J. M. Sierra (Eds.), Motivation and foreign language learning: From theory to 
practice (pp. 9-29). Philadelphia/Amsterdam: John Benjamins.

Dörnyei, Z., \& Murphey, T. (2003). Group dynamics in the language classroom. Cambridge. Cambridge University Press.

Dörnyei, Z., \& Ushioda, E. (2011). Teaching and researching motivation (2nd ed.). Harlow, UK: Longman.

Egbert, J. (2003). A study of flow theory in the foreign language classroom. Modern Language Journal, 87, 499-518.

Gaggioli, A., Milani, L., Mazzoni, E., \& Riva, G. (2011). Networked flow: A framework for understanding the dynamics of creative collaboration in educational and training settings. The Open Education Journal, 4(1), 41-49.

Gardner, R. C. (2001). Integrative motivation and second language acquisition. In Z. Dörnyei \& R. Schmidt (Eds.), Motivation and second language acquisition (pp 1-20). Honolulu, HI: University of Hawai’i Press.

Henry, A. (2011). Examining the impact of L2 English on L3 selves: A case study. International Journal of Multilingualism, 8, 235-255.

Henry, A. (2015). The dynamics of L3 motivation: A longitudinal interview/observationbased study. In Z. Dörnyei, P. D. MacIntyre, \& A. Henry (Eds.), Motivational dynamics in language learning (pp. 83-94). Bristol, UK: Multilingual Matters.

Henry, A. (in press a). Swedish or English? Migrants' experiences of the exchangeability of language resources. Journal of Bilingualism and Bilingual Education. DOI: $10.1080 / 13670050.2015 .1008979$

Henry, A. (in press b). Enablements and constraints: Inventorying affordances associated with lingua franca English. Journal of Bilingualism and Bilingual Education. DOI: $10.1080 / 13670050.2015 .1014465$

Levin, I. M. (2000). Vision revisited: Telling the story of the future. Journal of Applied Bevhavioral Science 36, 91-107. 
Li Wei (2011). Moment analysis and translanguaging space: Discursive construction of identities by multilingual Chinese youth in Britain. Journal of Pragmatics, 43, 12221235.

Locke, E. A., \& Latham, G. P. (1990). A theory of goal setting and task performance. Englewood Cliffs, NJ: Prentice Hall.

Markus, H., \& Nurius, P. (1986). Possible selves. American Psychologist, 41, 954-969.

Miller, R. B., \& Brickman, S. J. (2004). A model of future-oriented motivation and selfregulation. Educational Psychology Review, 16(1), 9-33.

Muir, C., \& Dörnyei, Z. (2013). Directed Motivational Currents: Using vision to create effective motivational pathways. Studies in Second Language Learning and Teaching, 3, 357-375.

Murphy, L. (2011). 'Why am I doing this?’ Maintaining motivation in distance language learning. In G. Murray, X. Gao, \& T. Lamb (Eds.), Identity, motivation and autonomy in language learning (pp. 107 - 124). Bristol, UK: Multilingual Matters.

Murray, G. (2011). Imagination, metacognition and the L2 self in a self-access learning environment. In G. Murray, X. Gao, \& T. Lamb (Eds.), Identity, motivation and autonomy in language learning (pp. 75-90). Bristol, UK: Multilingual Matters.

Norton, B. (2013). Identity and language learning: Extending the conversation. Bristol, UK: Multilingual Matters.

Norton, D. L. (1976). Personal destinies. Princeton, NJ: Princeton University Press.

Sawyer, R. K. (2006). Group creativity: Musical performance and collaboration. Psychology of Music, 34(2), 148-165.

Schernoff, D. (2013). Flow in the classroom. Education Week. Accessed (2015-01-15) from http://blogs.edweek.org/teachers/classroom_qa_with_larry_ferlazzo/2013/03/response_fl ow_in_the_classroom.html

Samata, S. (2014). The cultural memory of language. London: Bloomsbury. 
Sheldon, K. M., \& Elliot, A. J. (1998). Not all personal goals are personal: Comparing autonomous and controlled reasons for goals as predictors of effort and attainment. Personality and Social Psychology, 24(5), 546-557.

Sheldon, K. M., \& Elliot, A. J. (1999). Goal striving, need satisfaction, and longitudinal wellbeing: the self-concordance model. Journal of Personality and Social Psychology, 76(3), 482-497.

Sheldon, K. M., \& Houser-Marko, L. (2001). Self-concordance, goal attainment, and the pursuit of happiness: Can there be an upward spiral? Journal of Personality and Social Psychology, 80(1), 152-165.

Smith, J. A., \& M. Osborn. (2008). Interpretative phenomenological analysis. In J. A. Smith (Ed.) Qualitative Psychology (2nd ed., pp. 53-80). London: SAGE.

Straub, J. (2006). Understanding cultural differences: Relational hermeneutics and comparative analysis in cultural psychology. In J. Straub, D. Weidemann, C. Kolbl, \& B. Zielke (Eds.), Pursuit of meaning: Advances in cross-cultural psychology (pp. 163-214). Bielefeld: Transcript Verlag.

Ushioda, E. (2011). Motivating learners to speak as themselves. In G. Murray, X. Gao, \& T Lamb (Eds.), Identity, motivation and autonomy in language learning (pp. 11-24). Bristol, UK: Multilingual Matters.

Waninge, F., Dörnyei, Z., \& de Bot, K. (2015). Motivational dynamics in language learning: Change, stability and context. Modern Language Journal, 98(3) 704-723.

Waterman, A. S. (2008). Reconsidering happiness: A eudaimonist's perspective, The Journal of Positive Psychology 3(4), 234-252.

Yashima, T. \& Arano, K. (2015). Understanding EFL learners’ motivational dynamics: A three-level model from a dynamics systems and sociocultural perspective. In Z. Dörnyei, P. D. MacIntyre , \& A. Henry (Eds.), Motivational dynamics in language learning (pp. 285-314). Bristol, UK: Multilingual Matters. 
Zimmerman, D. (1998). Identity, context, interaction. In C. Antaki \& S. Widdicombe (Eds.), Identities in talk (pp. 87-106). London: SAGE. 